\title{
Vitamin B12 Deficiency in Older Diabetic Patients: Is it Necessary to Create Guidelines for Early Diagnosis, Monitoring and Treatment of this Nutritional Problem?
}

\section{Dominique Masferrer ${ }^{1 *}$ and Hugo Sánchez ${ }^{2}$}

${ }^{1}$ Department of Nutrition, Faculty of Medicine, University of Chile, Chile

${ }^{2}$ Public Nutrition Unit, Institute of Nutrition and Food Technology (INTA), University of Chile, Chile

According to reports from the World Health Organization, the aging population in both developed and in developing countries it has been possible due an improvement in access and coverage of health systems which has enabled a reduction in overall mortality rates and increased life expectancy of individuals [1]. However, this situation represents a challenge because it is necessary to maintain the achievements made in health and also generate environmental and sanitary conditions to ensure healthy aging and prevent pharmacological latrogenesis during the treatment of chronic diseases.

Considering that the nutrition in the elderly is a key element to achieving a good health, is essential to identify the requirements of critical nutrients during the aging. Among nutritional factors, vitamin B12 is essential for healthy aging. Vitamin B12 deficiency is associated with psychiatric and neurological diseases such as peripheral neuropathy and cognitive impairment $[2,3]$ and hematological diseases (megaloblastic anaemia) [4]. Moreover, low serum vitamin B12 levels are associated with an increase of serum total homocysteine concentrations and increased cardiovascular risk $[5,6]$.

Vitamin B12 deficiency is common in older adults and is considered a worldwide public health problem [7-10]. International health agencies recommend that adults over the age of 50 get most of vitamin B12 from supplements or fortified foods [11]. However, these recommendations are not always considered by health professionals when they are prescribing dietary guidelines for older adults.

In this context, the situation of elderly diabetics it is worrying because apparently they would have an additional risk factor for the development of this nutritional problem. Several studies have identified that prolonged use of high doses of metformin represent a risk factor for vitamin B12 deficiency [12-17]. Considering that the use of this drug is recommended at the time of the diagnosis of disease (in addition of changes in lifestyles), the time of exposure to this risk factor would be quite extensive. It is estimated that after 10-12 years of use of this drug, clinical signs of vitamin B12 deficiency are evident [12], a period that represents an opportunity to be prevented the appearance of this nutritional problem.

According to what is stated in the literature review for Mazokopakis et al. [12] the relationship between metformin use and the associated risk to develop vitamin B12 deficiency is described in diabetic patients since 1969. Since then, observational and clinical studies have confirmed this association but the mechanisms of this association are still unclear. However, some authors note that this studies have presented methodological limitations, which have been related to the use of serum or plasma vitamin B12 levels as the sole indicator of vitamin B12 deficiency, despite that methylmalonic acid and holotranscobalamin measurements have changed the clinical practice of diagnosing B12 deficiency in recent years $[12,18]$. Other limitations of these studies have been the large variability in the dose and duration of metformin therapy [12].
Despite the disagreements on the relationship between metformin use and risk of vitamin B12 deficiency, Diabetes Mellitus type 2 is one of the conditions that produce more disease burden in the world [19] and the risk that older adults develop B12 deficiency is high [20-22], therefore is important to create guidelines that enhance the importance of monitoring serum levels of this vitamin and screening mechanisms to enable timely diagnosis of this nutritional problem in the elderly population and specifically those who are diabetic.

\section{References}

1. World Health Organization (2014) 10 facts on ageing and the life course. Facts Files.

2. Clarke R (2006) Vitamin B12, Acid Folic, and the Prevention of dementia. N Engl J Med 354: 2817-2819.

3. Eussen SJ, de Groot LC, Joosten LW (2006) Effect of oral vitamin B-12 with or without folic acid on cognitive function in older people with mild vitamin B-12 deficiency. Am J Clin Nutr 84: 361-370.

4. Snow CF (1999) Laboratory diagnosis of vitamin B12 and folatedeficiency: a guide for the primary care physician. Arch Intern Med 159: 1289-1298.

5. Welch GN, Loscalzo J (1998) Homocysteine and atherothrombosis. N Engl $J$ Med 338: 1042-1050.

6. Herrmann W, Schorr H, Obeid R, Geisel J (2003) Vitamin B-12 status particularly holotranscobalamin II and methylmalonic acid concentrations, and hyperhomocysteinemia in vegetarians. Am J Clin Nutr 78: 131-136.

7. Campbell A, Millar J, Green R, Hann M, Allen L (2003) Plasma Vitamin B12 concentrations in an Elderly Latino population are predicted by serum Gastrin concentrations and crystalline vitamin B12 intake. J Nutr 9: 2770-2776.

8. Carmel R, Green R, Rosenblat DS, Watkins D (2003) Update on cobalamin, folate and homocysteine. Hematology $62-81$

9. Clarke R, Evans G, Schneede J, Nexo E, Bates C, et al. (2004) Vitamin B12 and folate deficiency in later life. Age Ageing 33: 34-41.

10. Sánchez H (2010) Déficit de vitamina B-12 en adultos mayores: ¿Un problema de salud pública en Chile? Rev. méd. Chile 138: 44-52.

11. Institute of Medicine, Food and Nutrition Board (1998) Dietary Reference Intakes: Thiamin, Riboflavin, Niacin, Vitamin B6, Folate, Vitamin B12, Pantothenic Acid, Biotin, and Choline. National Academy Press, Washington DC, USA.

*Corresponding author: Dominique Masferrer, Researcher, Department of Nutrition, University of Chile, Avenida Independencia 1027, Santiago, Chile, Tel: 56229781460; E-mail: dominique.masferrer@gmail.com

Received November 12, 2014; Accepted December 23, 2014; Published December 25, 2014

Citation: Masferrer D, Sánchez H (2014) Vitamin B12 Deficiency in Older Diabetic Patients: Is it Necessary to Create Guidelines for Early Diagnosis, Monitoring and Treatment of this Nutritional Problem? J Diabetes Metab 6: 487. doi:10.4172/2155 6156.1000487

Copyright: (c) 2014 Masferrer D, et al. This is an open-access article distributed under the terms of the Creative Commons Attribution License, which permits unrestricted use, distribution, and reproduction in any medium, provided the original author and source are credited. 
Citation: Masferrer D, Sánchez H (2014) Vitamin B12 Deficiency in Older Diabetic Patients: Is it Necessary to Create Guidelines for Early Diagnosis, Monitoring and Treatment of this Nutritional Problem? J Diabetes Metab 6: 487. doi:10.4172/2155-6156.1000487

Page 2 of 2

12. Mazokopakis EE, Starakis IK (2012) Recommendations for diagnosis and management of metformin-induced vitamin B12 (Cbl) deficiency. Diabetes Res Clin Pract 97: 359-367

13. Kang D, Yun JS, Ko SH, Lim TS, Ahn YB, et al. (2014) Higher prevalence of metformin-induced vitamin B12 deficiency in sulfonylurea combination compared with insulin combination in patients with type 2 diabetes: a crosssectional study. PLoS One 9: e109878.

14. Sánchez H, Masferrer D, Lera L, Arancibia E, Angel B, et al. (2014) Vitamin B12 deficiency associated with high doses od metformin in older people diabetic. Nutr Hosp 29: 1394-1400.

15. Tung ML, Tan LK (2014) Long term use of metformin leading to vitamin B 12 deficiency. Diabetes Res Clin Pract 104: e75-76

16. Beulens JW, Hart HE, Kuijs R, Kooijman-Buiting AM, Rutten GE (2014) Influence of duration and dose of metformin on cobalamin deficiency in type 2 diabetes patients usingmetformin. Acta Diabetol.
17. de Jager J, Kooy A, Lehert P, Wulffele' MG, van der Kolk J, et al. (2010) Long term treatment with metformin in patients with type 2 diabetes and risk of vitamin B-12 deficiency: randomised placebo controlled trial. BMJ 340: c2181.

18. Obeid R (2014) Metformin Causing Vitamin B12 Deficiency: A Guilty Verdict Without Sufficient Evidence. Diabetes Care 37: e22-e23.

19. Barceló A, Aedo C, Rajpathak S, Robles S (2003) The cost of diabetes in Latin America and the Caribbean. Bull World Health Organ 81: 19-27.

20. McLean E, de Benoist B, Allen LH (2008) Review of the magnitude of folate and vitamin B12 deficiencies worldwide. Food Nutr Bull 29: S38-51.

21. Allen LH (2009) How common is vitamin B-12 deficiency? Am J Clinn Nutr 89: 693S-696S.

22. Allen L (2004) Folate and vitamin B12 status in the Americas. Nutr Rev 62: 29-33. 